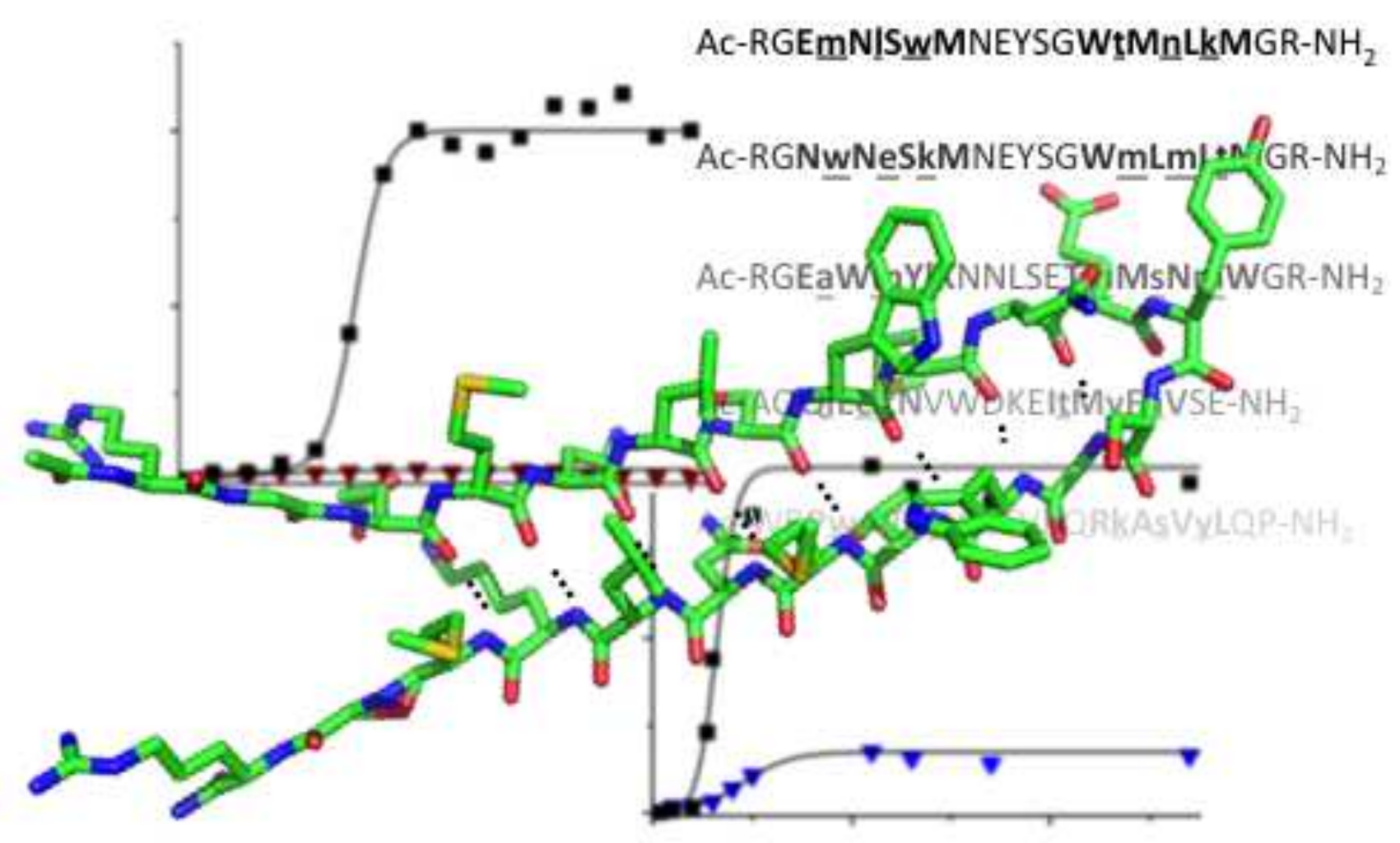


March 6, 2016

Revised

\title{
Peptides Comprised of Alternating L- and D- Amino Acids Inhibit Amyloidogenesis in Three Distinct Amyloid Systems Independent of Sequence
}

\author{
Jackson Kellock $^{1}$, Gene Hopping ${ }^{1}$, Byron Caughey ${ }^{2}$, Valerie Daggett ${ }^{1}$ \\ 1 - Department of Bioengineering, University of Washington, Seattle, WA 98105-5013, USA \\ 2 - Laboratory of Persistent Viral Diseases, Rocky Mountain Laboratories, National Institute \\ of Allergy and Infectious Diseases, National Institutes of Health, Hamilton, MT 59840-2932, \\ USA
}

Correspondence to Valerie Daggett: Department of Bioengineering, University of Washington,

Seattle, WA 98105-5013, USA.daggett@uw.edu

(C) 2016. This manuscript version is made available under the Elsevier user license http://www.elsevier.com/open-access/userlicense/1.0/ 


\begin{abstract}
There is now substantial evidence that soluble oligomers are primary toxic agents in amyloid diseases. Development of an antibody recognizing the toxic soluble oligomeric forms of different and unrelated amyloid species suggests a common conformational intermediate during amyloidogenesis. We previously observed common occurrence of a novel secondary structure element, which we call $\alpha$-sheet, in molecular dynamics simulations of various amyloidogenic proteins, and we hypothesized that the toxic conformer is comprised of $\alpha$-sheet structure. As such, $\alpha$-sheet may represent a conformational signature of the misfolded intermediates of amyloidogenesis and a potential unique binding target for peptide inhibitors. Recently, we reported the design and characterization of a novel hairpin peptide ( $\alpha 1$ or AP90) that adopts stable $\alpha$-sheet structure and inhibits the aggregation of the $\beta$-Amyloid Peptide $A \beta 42$, and transthyretin. AP90 is a 23-residue hairpin peptide featuring alternating D- and L- amino acids with favorable conformational propensities for $\alpha$-sheet formation, and a designed turn. For this study, we reverse engineered AP90 to identify which of its design features is most responsible for conferring $\alpha$-sheet stability and inhibitory activity. We present experimental characterization (CD and FTIR) of 7 peptides designed to accomplish this. In addition, we measured their ability to inhibit aggregation in three unrelated amyloid species: A $\beta 42$, transthyretin, and human islet amylin polypeptide. We found that a hairpin peptide featuring alternating L- and D-amino acids, independent of sequence, is sufficient for conferring $\alpha$-sheet structure and inhibition of aggregation. Additionally, we show a correlation between $\alpha$-sheet structural stability and inhibitory activity.
\end{abstract}

KEYWORDS: Beta Amyloid, Amyloid, Toxic Oligomer, Inhibitor, $\alpha$-sheet 
Abbreviations: $\mathrm{AD}$, Alzheimer's disease; $\mathrm{MD}$, molecular dynamics; $\mathrm{CD}$, cicrular dichroism spectroscopy; NOESY, Nuclear Overhauser effect spectroscopy; A $\beta 42$, Amyloid Beta (1-42); IAPP, Islet Amyloid Polypeptide; TTR, Transthyretin; CR, Congo Red; ThT, Thioflavin T;

HFIP, hexafluoro - 1, 1, 1, 3, 3, 3 - isopropanol 


\section{Introduction}

Over 40 distinct human amyloid diseases have been identified, many of which contribute to severe neurodegeneration and organ dysfunction [1]. Amyloid diseases are associated with the aggregation of normally-soluble peptides or proteins to insoluble, $\beta$-rich amyloid deposits [2,3]. Multiple aggregation pathways are thought to be available to amyloidogenic species, with different pathways furnishing multiple distinct conformational intermediates [4-6]. The mechanism of amyloid assembly and its associated pathology are not well understood; however, there is substantial experimental evidence that the soluble oligomeric intermediates populated during amyloidosis are the primary species responsible for cellular toxicity [7-10].

The development of conformation-specific antibodies recognizing the toxic oligomeric intermediates of many different amyloid peptides and proteins suggests a common backbone structure associated with amyloidogenic intermediates $[11,12]$; this is supported by the crossreactivity of different, unrelated amyloid proteins and peptides [13-17]. Proposed amyloid oligomer models in the literature are widely variant, including helix-containing assemblies $[18,19]$, extended $\beta$-sheets resembling small fibrillar structures [20], $\beta$-barrels [21-24], looselystructured assemblies [25], and spiraling sheets [26]; the apparent availability of multiple aggregation pathways allows for structurally and compositionally diverse intermediates, each associated with one of many aggregation pathways. Notably, NMR experiments do not detect $\beta$ sheet or $\alpha$-helix structure in toxic $A \beta 42$ (Amyloid $\beta$-peptide residues 1-42) pentamers and hexamers [25], a finding corroborated by the absence of $\beta$-sheet or $\alpha$-helix fingerprints in CD spectra taken during the lag (or nucleation) phases of polyglutamine, $A \beta 42$, islet amylin polypeptide (IAPP), and $\alpha$-synuclein aggregation [27-32]. 
Previous analysis of low-pH molecular dynamics (MD) simulations of the misfolding of various amyloidogenic proteins showed common occurrence of a novel secondary structure called $\alpha$-sheet [33-36]. $\alpha$-sheet secondary structure is defined by the alternation of $\alpha_{L}$ and $\alpha_{R}$ conformations through sequential amino acid residues, resulting in the parallel alignment of all carbonyl groups and all amide protons on opposite faces of the peptide strand (Fig. 1). This alignment of identical functional groups promotes cross-strand hydrogen bonding for sheet-type structure. Based on the shared presence of $\alpha$-sheet structure across these simulations, we proposed that $\alpha$-sheet is a structural signature of the misfolded intermediates of amyloidogenesis, and that $\alpha$-sheet secondary structure might provide a binding target for potential inhibitors of amyloid formation [36]. Our recent studies have demonstrated that designed $\alpha$-sheet peptides ( 20 residues) effectively inhibit amyloid formation by binding to toxic oligomeric intermediates [37]. We hypothesize that the mechanism of binding is a backbone-backbone intermolecular interaction between $\alpha$-strand segments. Among these $\alpha$-sheet inhibitors was a 23 -residue designed $\alpha$-hairpin named $\alpha 1$, which we refer to here as AP90 (Fig. 1). The AP90 design exploits alternating D- and L- C $\alpha$ chirality through its $\alpha$-strand segments to stabilize the alternating $\alpha_{L}$ and $\alpha_{R}$ amino acid conformations necessary for $\alpha$-sheet structure. The spectroscopic properties of AP90 have been characterized, and they provide evidence for stable $\alpha$-sheet structure [37]. The CD spectrum of AP90 is relatively featureless, as is expected for a peptide with alternating D- and L- amino acids. Its FTIR spectrum features a strong absorbance peak centered near $1675 \mathrm{~cm}^{-1}$ and a shoulder centered at $1640 \mathrm{~cm}^{-1}$, both of which match theoretical predictions for $\alpha$-sheet FTIR absorbance [38]. AP90 also gives NH-NH NOESY couplings among amide protons of sequential $(i, i+1)$ residues, indicating the alignment of 
successive $\mathrm{NH}$ and $\mathrm{C}=\mathrm{O}$ groups, characteristic of $\alpha$-sheet. Furthermore, AP90 lacks the characteristic signals of $\alpha$-helix and $\beta$-structure.

In this study, we explored the relative importance of the design features of AP90 in conferring $\alpha$-sheet structure and inhibitory activity against amyloid formation by reverse engineering the peptide. Specifically, we designed peptides that successively eliminate features presumed to stabilize the structure, and we experimentally characterized the spectroscopic properties and inhibitory activity of these resulting peptides. Three amyloidogenic species were chosen to examine general inhibitory activity of the designs: the A $\beta 42$ peptide associated with Alzheimer's disease [9], amylin or IAPP associated with type 2 diabetes [39], and transthyretin (TTR), which is associated with peripheral polyneuropathy and systemic senile amyloidosis [40]. Aggregation for each of these amyloid species can be monitored by dye-binding assays [41,42], allowing quantitation of inhibition against aggregation.

Our study of the AP90 parent and its derivatives revealed that all of the peptides templated to have alternating L- and D-chirality possess inhibitory activity against amyloid formation independent of sequence, although the sequence can modulate the strength of the inhibition. In addition, there is a correlation between $\alpha$-sheet structural stability and activity that supports our hypothesis that $\alpha$-sheet is a structural signature of intermediates during amyloid formation.

\section{Results and Discussion}

\section{Deconstructing determinants of inhibition}


Our initial interest was in determining which of AP90's design features were most responsible for both stabilizing $\alpha$-sheet secondary structure and conferring inhibitory activity in amyloidogenic systems. The AP90 design was constructed from a 23-residue hairpin template featuring two $\alpha$-strands joined by a central turn. The template contains D chirality at the C $\alpha$ of strand residues 4, 6, 8, 16, 18, and 20 (Fig. 1). This sequence template is referred to henceforth as the "L/D template." In an attempt to optimize stability, AP90's strand segments are composed of amino acids with favorable propensities for either the $\alpha_{L}$ or $\alpha_{R}$ conformations $[43,44]$. Additionally, AP90 features a 5-residue designed turn (-NEYSG-) [34] to promote cross-strand hydrogen bonding. The N- and C-termini of AP90 are capped with Ac-RG- or -GR-NH respectively, for improved solubility [45]. Solubility is a particularly important concern for side chain selection as well, because aggregation is critical to toxicity and we want to ensure that our $\alpha$-sheet designs are nontoxic.

The peptides reported here were designed to study the contributions of these various sequence elements of the AP90 parent design to $\alpha$-hairpin structure and inhibitory activity. The particular elements selected for study include: the presence of a designed turn; amino acid conformational propensity; and, the L/D template. For our design process, we proceeded from the assumption that the AP90 peptide represents an optimized design. Our sequential design modifications to this parent sequence used sequence randomization through the L/D template of AP90 to successively eliminate the peptide's design features and, presumably, destabilize $\alpha$ sheet structure. Our expectation was that increasing destabilization would be confirmed and monitored by reduced inhibitory activity and changes in predicted spectroscopic hallmarks. Modifications gradually decreased sequence similarity to the AP90 parent, an effect we represented using sequence identity relative to AP90. The designs are listed in Table 1 . They are 
assigned to one of two groups: peptides that follow the L/D template ("templated" designs) and peptides that do not ("non-templated" designs). They are ordered according to sequence identity relative to AP90.

\section{Main chain structure responsible for inhibition independent of sequence}

Inhibition experiments were used to study which of AP90's design features confer general inhibitory activity. Inhibitory activity was measured by co-incubating peptide designs with each of the amyloid species A 342 , IAPP, and TTR at suitable conditions for in vitro aggregation; aggregation was then quantitated by a dye-binding assay using either Thioflavin $\mathrm{T}$ (ThT) fluorescence (Aß42 and IAPP) or Congo Red (CR) absorbance (TTR). Unfortunately, the inability to apply a single dye-binding assay to several different amyloidogenic species is a recurring problem in the relevant literature $[45,46]$.

We have previously shown that the AP90 lead compound is an inhibitor of A $\beta 42$ and TTR aggregation at conditions similar to those reported here. Under the assay conditions used for this study, AP90 nearly completely abolished A $\beta 42$ aggregation when co-incubated at 4-fold excess (Fig. 2a, Table 2). Co-incubation of AP90 with IAPP at an 8-fold excess resulted in 83\% inhibition of aggregation (Table 2). Co-incubation of AP90 with TTR at a 10-fold excess resulted in 65\% inhibition of aggregation (Table 2). All modified designs were evaluated relative to the parent AP90. Representative traces for inhibition experiments involving all designs are included in Figure 2 and the average inhibition values and associated error over 3 independent trials are provided in Table 2.

For our first design modification, we scrambled the sequence (retaining the amino acid composition) through AP90's $\alpha$-strand segments (residues 3-9 and 15-21) while maintaining the 
L/D template, RG tails, and designed turn (Fig.1). The resulting derivative (AP5) had 100\% retention of sequence composition and chirality but only $65 \%$ sequence identity relative to AP90, and it demonstrated nearly identical inhibitory activity against $A \beta 42$ and improved inhibition against IAPP, with activity against TTR reduced to $37 \%$ inhibition (Table 2). However, because AP90's $\alpha$-strand residues all possess favorable conformational propensities, scrambling only through strand segments likely produced little destabilization. That scrambling the strand sequences did not affect inhibitory potency demonstrates that the sequence per se is not determining activity - the same inhibitory effect is achieved with an alternate amino acid order.

To both remove any stabilizing effect of the designed turn and introduce amino acids lacking high $\alpha$-sheet propensity into the strand segments, we next scrambled the sequence through both $\alpha$-strands and the turn (residues 3-21), while again maintaining the L/D template and RG tails. This yielded a peptide (AP6) with only 25\% sequence identity to the parent AP90. Co-incubation of AP6 with amyloid species gave 35\% inhibition against A $\beta 42$ and $75 \%$ inhibition of IAPP, thereby displaying significantly reduced activity due to the loss of the designed turn relative to both AP90 and AP5 (Table 2). AP6 interfered with Congo Red binding to TTR, preventing quantitation of its inhibition of TTR amyloidosis using the CR-binding assay. Unfortunately, several subsequent designs were similarly unsuitable for the Congo Red binding assay, and they had to be evaluated by an alternative method, as discussed further below.

To further test the apparent resilience of the L/D template in conferring inhibitory activity, we randomly selected amino acids for all 23 residues while maintaining the L/D template. This design choice was intended to decouple effects due to the $\mathrm{L} / \mathrm{D}$ template from any composition-specific effects. Random selection yielded two designs (AP3 and AP4) with less 
than $20 \%$ sequence identity to AP90. Neither design showed uniformly high inhibition across all systems studied: AP3 inhibited $36 \%$ of the IAPP aggregation but only $11 \%$ of the A $\beta 42$ aggregation (Table 2). AP4 inhibited $42 \%$ of the A $\beta 42$ aggregation and $11 \%$ of IAPP aggregation (Table 2). Like AP6, both AP3 and AP4 were unsuitable for the CR-binding assay due to interference with the dye.

Two additional peptides were designed without the L/D template: $\mathrm{P} 2$ is a scramble of the AP90 parent sequence that does not enforce alternating L- and D- chirality through strand segments, while P90 is an all-L-amino acid analog of AP90 (Table 1). The non-templated, scrambled AP90 sequence, P2, was inactive against both A 342 and IAPP aggregation (Table 2). Like several of the other designs, P2 bound Congo Red so that the TTR assay could not be performed and only inhibition of A $\beta 42$ and IAPP aggregation could be measured. The inactivity of P2 demonstrates the necessity of the L/D template for conferring inhibitory activity. Additionally, it shows that the absolute amino acid composition of AP90, AP5, AP6, and P2 (all $100 \%$ ) is not responsible for activity, as all of the L/D template peptides inhibit amyloid formation to some degree while a peptide utilizing the same amino acids as AP90, AP5 and AP6 but lacking the $\mathrm{L} / \mathrm{D}$ template does not. This also shows that it is not the $\mathrm{D}$-amino acids per se that are responsible for inhibition in the templated designs.

Eliminating D-chirality from the AP90 sequence resulted in a completely insoluble peptide (P90) despite the unchanged isoelectric point and side chains (relative to AP90). Due to this lack of solubility, inhibition experiments could not be performed with P90. Note that the AP90 and P90 peptides contain exactly the same chemical sequence but 6 of the residues in 


\begin{abstract}
AP90 have D-chirality to impose templating of the $\alpha$-sheet structure (Table 1). The difference in the behavior of AP90 and P90 is striking.
\end{abstract}

Unfortunately the inhibition (or lack thereof) of TTR could not be evaluated for many of the designs due to their binding to Congo Red. Consequently we also evaluated the compounds in a more qualitative binding assay involving immobilization of the designs to agarose beads and then determining whether they preferentially bind pre-incubated toxic TTR samples, as described earlier [37]. We have previously shown that AP90 preferentially binds toxic but not nontoxic solutions of $A \beta 42$ and TTR [37], consistent with our $\alpha$-sheet hypothesis. In line with the A $\beta 42$ and IAPP inhibition results, the L/D templated designs all bind species from the pre-incubated toxic TTR solutions while the non-templated designs do not, and in this case P90 could also be evaluated because its self-aggregation is controlled through immobilization on the beads (Fig. 3, Table 2).

Successive elimination of design features resulted in a decrease in binding to the toxic oligomeric species as probed by the agarose bead binding experiment with TTR or as reflected in the inhibition of fibril formation by binding of the oligomeric precursor to the fibrillar state. This decrease correlated with decreasing sequence identity relative to AP90 (Fig. 4), confirming the predicted effects of our design modifications. Despite our sequence modifications, however, we were unable to fully quench inhibition by the L/D templated peptides, as both the completely randomized designs, AP3 and AP4, inhibited amyloid aggregation and/or preferentially bound the TTR toxic oligmers. Our inability to abolish inhibition suggests that the L/D chirality template is predominantly responsible for conferring inhibitory activity to our designs, rather than the nature of the side chains, the absolute composition, or the designed turn. Even without a well-designed turn or residues with high propensity to form $\alpha$-strands, the L/D template confers 
meaningful inhibitory activity and the ability to distinguish between nontoxic and toxic conformers. Consequently, the L/D template appears to be a novel structural template for design of general inhibitors of amyloidosis whose mechanism of inhibition appears to be distinct from any previously reported peptides or organic molecules.

\section{Destabilization of $\alpha$-sheet structure lowers inhibition}

In order to assess the structural effects of our design modifications, CD spectra were recorded for all peptides (Fig. 4a). Due to the variable solubility and to ensure solubility of all designs and uniformity of solution conditions, all CD spectra were taken in phosphate buffer with $50 \%$ acetonitrile (v/v). The presence of acetonitrile did not significantly affect the CD spectra of the very soluble compounds and allowed us to record the spectra of non-templated designs that are not as soluble under aqueous conditions.

Featureless spectra were anticipated for peptides including alternating L- and D-amino acids due to the opposite absorption of circularly polarized light [37]. A CD signal near $195 \mathrm{~nm}$ is typically attributed to unstructured conformers, often being referred to as the 'random coil' signal, and if it is due to the L-amino acids the signal is negative and positive for D-amino acids. We have therefore interpreted larger negative signals near $195 \mathrm{~nm}$ as being due to distortions of the turn and fraying of the ends of the hairpin upon modification, as both of these regions are comprised of L-amino acids. Furthermore, the coupling of a single chiral $\mathrm{C} \alpha$ and N-terminal peptide bond is sufficient for production of a CD minimum near $200 \mathrm{~nm}$ [48]. So, while a negative signal in this region is typically taken to represent "random coil", it is potentially more complicated involving dynamic exchange between many non-random conformers, particularly after loss of the turn. As such, we take a more negative minimum near 195-200 nm to reflect a 
change in the dynamics and structure away from the AP90 state without being able to precisely describe the detailed nature of the changes.

In any case, the first of our design modifications involving shuffling of the residues in the strands (AP5) resulted in a CD spectrum very similar to that of AP90, each with a relatively featureless, flat region between 210-260 nm and a minimum near $195 \mathrm{~nm}$ (Fig. 4a). In the spectrum of AP6, which is due to shuffling of the strands and the turn residues, there is a broad shoulder centered at roughly $215 \mathrm{~nm}$ (extending to $225 \mathrm{~nm}$ ) that suggests the possibility of some $\beta$-character among the L-amino acids. The randomly selected sequences (AP3, AP4) both gave a relatively strong CD minimum shifted from 195 to $200 \mathrm{~nm}$. AP4's spectrum features an additional band at $224 \mathrm{~nm}$ that resembles that characteristic of L-Trp absorbance. Notably, a similar minimum was not observed in the CD spectra of the L-Trp-bearing designs AP90, AP5, AP6, or AP3, all of which follow the L/D template.

Among the five templated peptides, the CD minimum $\left([\Theta]_{\min }\right)$ near $195 \mathrm{~nm}$ shifted to 200 $\mathrm{nm}$ and increased in magnitude with each of our sequential design modifications (Table 3), indicating increasing random coil character among their L-amino acids. $[\Theta]_{\min }$ is strongest in the spectra of AP3 and AP4, the two peptides expected to possess the lowest $\alpha$-sheet stability. $[\Theta]_{\min }$ also red-shifted among templated peptides with sequentially destabilizing modifications, possibly due to contributions of $\alpha$-helix and $\beta$-sheet conformations transiently populated by the destabilized peptide in the L-amino acid stretch [37].

Surprisingly, the CD spectrum for the scrambled design P2 is very similar to that of AP90. We expected a stronger minimum near $195 \mathrm{~nm}$. Regardless, P2's inactivity as an inhibitor 
suggests an absence of any structural feature - such as $\alpha$ - or $\beta$-sheet - that could confer activity. The CD spectrum of the all-L peptide P90 reflects weak $\beta$-sheet structure (Fig. 4a).

To further characterize sequence effects on structure, we recorded solid-state FTIR absorbance spectra for all AP90 derivatives (Fig. 4b). $\alpha$-sheet secondary structure produces FTIR bands that are distinct from characteristic $\beta$-sheet and $\alpha$-helix bands [38]. The FTIR absorbance spectrum for AP90 features a dominant peak at $1675 \mathrm{~cm}^{-1}$, with a shoulder centered at roughly $1640 \mathrm{~cm}^{-1}$; notably, these are the predicted features for $\alpha$-sheet absorbance spectra [38]. AP5, AP3, and AP4 gave dominant peaks at either 1640 or $1675 \mathrm{~cm}^{-1}$, suggesting that there are subtle differences in the $\alpha$-sheet structures. The FTIR absorbance spectra of AP4 and AP5 feature a broad band centered at $1640 \mathrm{~cm}^{-1}$. AP6 stands out with a dominant peak centered at $1620 \mathrm{~cm}^{-1}$ in the spectral region typically associated with $\beta$-sheet, and a broad shoulder near $1660 \mathrm{~cm}^{-1}$. In the past, we have found that the drying process required for the solid-state FTIR measurements can sometimes induce $\beta$-structure, an effect that might be at play here in the 7residue segment of L-amino acids in AP6.

The non-templated sequence P2 gave a narrow absorbance band centered near $1690 \mathrm{~cm}^{-1}$, with a shoulder near $1710 \mathrm{~cm}^{-1}$. The all-L-amino acid P90 showed a dominant FTIR band near $1620 \mathrm{~cm}^{-1}$ in the region associated with $\beta$-sheet, with a broad, weak shoulder at $1660 \mathrm{~cm}^{-1} . \mathrm{P} 90$ 's sequence includes a designed turn and several residues with high $\beta$-propensity, supporting FTIR identification of $\beta$-hairpin structure, consistent with its $\mathrm{CD}$.

We have previously hypothesized that $\alpha$-sheet secondary structure represents a conformational signature of toxic intermediates of amyloidosis [33-36]. Low-pH MD simulations provided the initial basis for this hypothesis, and subsequent design and 
experimental characterization of $\alpha$-sheet inhibitors of amyloidosis have supported our assertion [37]. Under the assumption that $\alpha$-sheet is a structural feature common to oligomeric intermediates, stable $\alpha$-hairpins were expected to inhibit amyloid formation in all three amyloid systems studied (A $\beta 42$, IAPP, and TTR) through backbone/backbone interactions between $\alpha$ sheet/strand segments. Because of the nature of this proposed inhibitory mechanism, a correlation between $\alpha$-hairpin structural stability and general inhibitory activity is expected.

As discussed above, increasing randomization of the sequences among the $\mathrm{L} / \mathrm{D}$ templated designs (represented quantitatively by sequence identity to AP90) correlated with an increase in magnitude and a shift of the CD minimum near 195 to $200 \mathrm{~nm}$ (Fig. 5, Table 3). Direct comparison of the $\mathrm{CD}$ and inhibition results (Fig. 5) illustrates the link between changes in the structure and decreasing inhibitory activity, a result consistent with an inhibitory mechanism featuring backbone/backbone intermolecular interactions. However, the side chains modulate the behavior of these templated L/D peptides in two main ways: (1) by affecting their structural stability, which when compromised leads to a drop in inhibition; and (2) by affecting the complementarity of the binding with the target amyloid $\alpha$-sheet species, as displayed by the different inhibition rankings. For example, for $\mathrm{A} \beta 42$ the compounds ranked as follows, from best to worst: AP90 AP5 > AP4 > AP6 > AP3. For IAPP the ranking is: AP5 > AP90 > AP6 > AP3 $>$ AP4.

Although the non-templated design P90 was expected to be an inactive, unstructured control, it contained $\beta$-character as evidenced by CD and FTIR (Fig. 4b). Inhibition results could not be obtained for P90 because it is insoluble in our aqueous assay conditions; however, it does not bind the toxic oligomer species of TTR, and instead preferentially binds native tetrameric 
TTR (Fig. 3). We have shown that a designed trpzip $\beta$-hairpin can inhibit TTR aggregation by binding to the native tetramer, while other $\beta$-hairpins do not [37,52]. $\beta$-hairpins are also known inhibitors of $\mathrm{A} \beta$ by binding the monomer, so it is possible $\mathrm{P} 90$ could inhibit aggregation, but it is far too insoluble and it would do so by a different mechanism than the templated L/D designs Nevertheless, the complete loss of solubility caused solely by the design's elimination of Dchirality further reflects a substantial structural change. This structural change associated with elimination of D-chirality demonstrates the remarkable effect of the L/D template.

\section{Conclusions}

Our results identify a new sequence template for $\alpha$-sheet peptide inhibitors of amyloidosis. Additionally, the apparent correlation between $\alpha$-sheet stability and inhibitory potency in our templated peptides supports an inhibitory mechanism featuring backbone/backbone interactions among $\alpha$-strand segments. The growing evidence for the association of $\alpha$-sheet with amyloidogenic intermediates identifies a new target for inhibitors of amyloidosis. Considering that we are only now characterizing the spectroscopic properties and inhibitory activity of $\alpha$-sheet peptides, we have much room for further optimization of both stability and activity. Future designs are expected to possess even higher inhibitory potency as we further inform our design process. Looking forward, potential therapeutic peptides following an L/D template could have an advantage in in vivo studies, as they should not be metabolized as rapidly as their all-L analogs. In addition, to further optimize our designs for inhibitory activity, we are now exploiting our proposed inhibitory mechanism to develop diagnostic assays for binding toxic oligomeric species from solution, and which may also aid in structural characterization of the toxic oligomers. 


\section{Materials and Methods}

\section{Materials}

Designed peptides were purchased from CPC Scientific or American Peptide Company (APC) and supplied as $\geq 95 \%$ purity as assessed by RP-HPLC and mass spectrometry. A $\beta 42$ and IAPP were also purchased from APC. Lyophilized A $\beta 42$ and IAPP were treated with 1,1,1,3,3,3hexafluoroisopropanol (HFIP) purchased from Sigma (St. Louis, Missouri) upon receipt and aliquotted from stock solutions made in HFIP. TTR purchased from Lee Biosolutions (St. Louis, Missouri) was dissolved to $10 \mathrm{mg} / \mathrm{mL}$ in $20 \mathrm{mM}$ ammonium carbonate buffer (pH 8.0) and aliquotted from this stock solution. Amyloid peptide/protein aliquots were dried under vacuum and stored at $-18^{\circ} \mathrm{C}$ until use.

\section{Solution Aggregation Assays}

A 342 was thawed from $-18^{\circ} \mathrm{C}$ and re-treated in HFIP for $30 \mathrm{~min}$. The HFIP was then removed under gentle air, and the resulting dry peptide was further exsiccated 30 min in a Thermo Scientific Savant SC110A SpeedVac. HFIP-treated A $\beta 42$ was dissolved to $0.75 \mathrm{mg} / \mathrm{mL}$ in $6 \mathrm{mM} \mathrm{NaOH}$ by sonication $(5 \mathrm{~min})$. The $0.75 \mathrm{mg} / \mathrm{mL}$ stock was filtered through a $0.22 \mu \mathrm{m}$ Costar Spin-X cellulose centrifuge filter, and its concentration was verified by UV/Vis absorbance at $220 \mathrm{~nm}\left(\varepsilon_{220}=50,000 \mathrm{M}^{-1} \mathrm{~cm}^{-1}\right)$ using a Thermo Scientific NanoDrop 2000 spectrometer [49]. The stock was allowed to rest $4 \mathrm{hr}$ at room temperature (RT) for $\mathrm{NaOH}$ treatment; aliquots were then portioned into wells of a Nunc 96-well fluorescence plate and diluted to $10 \mu \mathrm{M}$ A $\beta 42$ with PBS (11 mM phos, $152 \mathrm{mM} \mathrm{NaCl,} 3 \mathrm{mM} \mathrm{KCl,} 22 \mu \mathrm{M}$ ThT, pH 7.4) containing inhibitor peptide (inhibitor concentrations verified by Trp/Tyr UV/Vis abs at 280 
$\mathrm{nm}$ ). In the case of the less soluble AP6 and P2 peptides, 0.9\% DMSO was added. Plates were sealed and incubated away from light at RT. RT was chosen over $37^{\circ} \mathrm{C}$ because high temperatures are thought to favor fibril elongation over oligomerization for this system, and the oligomer is our intended binding target [50]. AFM imaging confirmed the presence of relatively short (rather than long) fibrils following incubation of $\mathrm{A} \beta 42$ at the conditions detailed above (not shown).

Dry IAPP was thawed from $-18^{\circ} \mathrm{C}$ and treated with HFIP, as described above. The HFIPtreated IAPP was dissolved to $1 \mathrm{mg} / \mathrm{mL}$ in DMSO. $1 \mathrm{mg} / \mathrm{mL}$ stock aliquots were portioned into wells of a 96-well fluorescence plate and diluted to $10 \mu \mathrm{M}$ nominal IAPP concentration with PBS (11 mM phos, $152 \mathrm{mM} \mathrm{NaCl}, 3 \mathrm{mM} \mathrm{KCl,} 22 \mu \mathrm{M}$ ThT, pH 7.4) containing inhibitor peptide (inhibitor concentrations verified by Trp/Tyr UV/Vis abs at $280 \mathrm{~nm}$ ). Plates were then sealed and incubated at $37^{\circ} \mathrm{C}$. The ThT fluorescence assay was carried out as described above.

Dry TTR was thawed from $-18^{\circ} \mathrm{C}$ and dissolved directly to $10 \mu \mathrm{M}$ TTR $(40 \mu \mathrm{M}$ monomer) in either low-pH acetate buffer (50 mM NaOAc, 100 mM KCl, 1 mM EDTA, pH 4.5) or neutral-pH PBS (11 mM phos, $152 \mathrm{mM} \mathrm{NaCl}, 3 \mathrm{mM} \mathrm{KCl}, \mathrm{pH} 7.4)$ containing inhibitor peptide. Samples were incubated at either $4^{\circ}$ (neutral $\mathrm{pH}$ ) or $37^{\circ} \mathrm{C}$.

\section{ThT Fluorescence Assay}

For the ThT fluorescence assay, plates were removed from incubation and read once per timepoint in a Tecan Safire ${ }^{2}$ plate reader $\left(\lambda_{\mathrm{ex}}=450 \mathrm{~nm}, \lambda_{\mathrm{em}}=480 \mathrm{~nm}\right)$. Plates were shaken prior to the initial (" $t=0 ")$ timepoint, but not prior to any subsequent timepoints.

\section{Congo Red Binding Assay}


For the CR-binding assay, three $10 \mu \mathrm{L}$ sample aliquots were each combined with $190 \mu \mathrm{L}$ of a $10 \mu \mathrm{M}$ CR solution made in PBS (11 mM phos, $152 \mathrm{mM} \mathrm{NaCl,} 3 \mathrm{mM} \mathrm{KCl}, \mathrm{pH} 7.4)$ in wells of a 96-well clear micro-plate (Falcon). The plate was then read for absorbance at $477 \mathrm{~nm}$ and $540 \mathrm{~nm}$, and CR binding was determined according to a previously published equation [37].

\section{Transthyretin Column Binding Assay}

Peptide designs were immobilized to the Pierce Amino Link resin following the manufacturer's instructions. Coupling and all further steps and analyses have been described by Hopping et al. [37]. Fresh, tetrameric TTR at neutral $\mathrm{pH}$ and pre-incubated toxic solutions of TTR at low $\mathrm{pH}$ (toxicity confirmed through cell-based assays using neuroblastoma cells) were prepared and applied to the column. Bound material was eluted with guanidine hydrochloride and analyzed by dot blot analysis. The difference between the binding of the toxic and nontoxic solutions was determined for each peptide, except AP3, which lacks a lysine and the N-terminus is acetylated preventing its coupling to the resin.

\section{Circular Dichroism Spectroscopy}

Dry peptide was dissolved to $90 \mu \mathrm{M}$ in 50/50 - AcCN/PB (10 mM phosphate, $\mathrm{pH} 7.4$ ). Concentrations were verified by Trp/Tyr UV/Vis absorbance. CD spectra were taken at $25^{\circ} \mathrm{C}$ on an Aviv model 420 spectrometer (Aviv Biomedical). The dynode voltage was monitored to ensure it was below 500 volts. Average values from 3 scans were plotted using the Origin 8 software (Originlab, Northhampton, MA). All spectra were smoothed using the Savitsky-Golay method with 5-12 points/window and polynomial order 2 . The smoothed data were subtracted from the raw data and the differences were minimal and evenly distributed around zero. 


\section{Fourier Transform Infrared Spectroscopy}

FTIR spectroscopy assays were carried out according to the method described by Hopping et al. without any deviations [37].

\section{Acknowledgements}

We thank Drs. James Bryers, David Baker, Cecilia Giachelli, Buddy Ratner, and Pat Stayton for generous use of equipment. We thank Dr. Tom Schmidlin for his advice on figure design. This study was funded by the W.H. Coulter Foundation Translational Research Partnership Program (to V.D.), grants from the National Science Foundation (CBET-0966977 to V.D.), the National Institute of Health (GM 95808 to V.D.), the Coins for Alzheimer's Research Trust (to V.D.), and the Intramural Research Program of the NIAID, NIH (to B.C.).

Author Contributions: J.K., G.H., B.C., and V.D. designed research; J.K., G.H., and B.C. performed experiments; J.K., G.H., B.C., and V.D. analyzed results; and all authors contributed to the writing of the paper. 


\section{References}

[1] Chiti F, Dobson CM. Amyloid formation by globular proteins under native conditions. Nat Chem Biol 2009;5:15-22.

[2] Lührs T et al. 3D structure of Alzheimer's amyloid- $\beta(1-42)$ fibrils Proc Natl Acad Sci U S A 2005;102:17342-17347.

[3] Jahn TR et al. The common architecture of cross-beta amyloid. J Mol Biol 2010;395:71727.

[4] Necula M, Kayed R, Milton S, Glabe CG. Small molecule inhibitors of aggregation indicate that amyloid beta oligomerization and fibrillization pathways are independent and distinct. J Biol Chem 2007;282:10311-24.

[5] Glabe CG. Structural classification of toxic amyloid oligomers. J Biol Chem 2008;283:29639-43.

[6] Benilova I, Karran E, De Strooper B. The toxic A $\beta$ oligomer and Alzheimer's disease: an emperor in need of clothes. Nat Neurosci 2012;15:349-57.

[7] Caughey, B. Lansbury, P.T. Protofibrils, pores, fibrils, and neurodegeneration: Separating the responsible protein aggregates from the innocent bystanders. Ann Rev Neurosci 2003;26:267-298.

[8] Bucciantini $\mathrm{M}$ et al. Inherent toxicity of aggregates implies a common mechanism for protein misfolding diseases. Nature 2002;416:507-11.

[9] Hardy J, Selkoe DJ. The amyloid hypothesis of Alzheimer's disease: progress and problems on the road to therapeutics. Science 2002;297:353.

[10] Kirkitadze MD, Bitan G, Teplow DB. Paradigm shifts in Alzheimer's disease and other neurodegenerative disorders: the emerging role of oligomeric assemblies. J Neurosci Res 2002;69:567-77.

[11] Kayed $\mathrm{R}$ et al. Common structure of soluble amyloid oligomers implies common mechanism of pathogenesis. Science 2003;300:486-9.

[12] Kayed $\mathrm{R}$ et al. Conformation dependent monoclonal antibodies distinguish different replicating strains or conformers of prefibrillar $A \beta$ oligomers. Mol Neurodegener 2010;5:57.

[13] Laurén J, Gimbel DA, Nygaard HB, Gilbert JW, Strittmatter SM. Cellular prion protein mediates impairment of synaptic plasticity by amyloid-beta oligomers. Nature 2009;457:1128-32.

[14] Schwarzman AL. Transthyretin sequesters amyloid beta protein and prevents amyloid formation Proc Natl Acad Sci U S A 1994;91:8368-8372.

[15] Liu L, Murphy RM. Kinetics of inhibition of beta-amyloid aggregation by transthyretin. Biochemistry 2006;45:15702-9.

[16] Chen S, Yadav SP, Surewicz WK. Interaction between human prion protein and amyloidbeta (abeta) oligomers: role of N-terminal residues. J Biol Chem 2010;285:26377-83.

[17] Du J, Cho PY, Yang DT, Murphy RM. Identification of beta-amyloid-binding sites on transthyretin. Protein Eng Des Sel 2012;25:337-45.

[18] Hebda JA, Miranker AD. The interplay of catalysis and toxicity by amyloid intermediates on lipid bilayers: insights from type II diabetes Annu Rev Biophys 2009;38:125-152. 
[19] Kirkitadze MD, Condron MM, Teplow DB. Identification and characterization of key kinetic intermediates in amyloid $\beta$-protein fibrillogenesis J Mol Biol 2001;312:11031119.

[20] Li Y, Ji C, Xu W, Zhang JZH. Dynamical stability and assembly cooperativity of $\beta$-sheet amyloid oligomers--effect of polarization. J Phys Chem B 2012;116:13368-73.

[21] De Simone A, Derreumaux P. Low molecular weight oligomers of amyloid peptides display beta-barrel conformations: a replica exchange molecular dynamics study in explicit solvent. J Chem Phys 2010;132:165103.

[22] Stroud JC, Liu C, Teng PK, Eisenberg D. Toxic fibrillar oligomers of amyloid- $\beta$ have cross- $\beta$ structure. Proc Natl Acad Sci U S A 2012;109:7717-22.

[23] Laganowsky A et al. Atomic view of a toxic amyloid small oligomer. Science 2012;335:1228-31.

[24] Cerf $E$ et al. Antiparallel $\beta$-sheet: a signature structure of the oligomeric amyloid $\beta$ peptide Biochem J 2009;421:415-423.

[25] Ahmed M et al. Structural conversion of neurotoxic amyloid-beta(1-42) oligomers to fibrils. Nat Struct Mol Biol 2010;17:561-7.

[26] DeMarco ML, Daggett V. From conversion to aggregation: protofibril formation of the prion protein Proc Natl Acad Sci USA 2004;101:2293-2298.

[27] Kayed R et al. Conformational transitions of islet amyloid polypeptide (IAPP) in amyloid formation in vitro J Mol Biol 1999;287:781-796.

[28] Huggins KNL et al. Designed hairpin peptides interfere with amyloidogenesis pathways: fibril formation and cytotoxicity inhibition, interception of the preamyloid state. Biochemistry 2011;50:8202-12.

[29] Huang TH, Yang DS, Fraser PE, Chakrabartty A. Alternate aggregation pathways of the Alzheimer beta-amyloid peptide. an in vitro model of preamyloid. J Biol Chem 2000;275:36436-40.

[30] Chen S, Ferrone FA, Wetzel R. Huntington's disease age-of-onset linked to polyglutamine aggregation nucleation. Proc Natl Acad Sci U S A 2002;99:11884-9.

[31] Gorman PM, Yip CM, Fraser PE, Chakrabartty A. Alternate aggregation pathways of the Alzheimer $\beta$-amyloid peptide: a $\beta$ association kinetics at endosomal $\mathrm{pH}$. J Mol Biol 2003;325:743-757.

[32] Kim JR, Muresan A, Lee KYC, Murphy RM. Urea modulation of $\beta$-amyloid fibril growth: experimental studies and kinetic models Protein Sci 2004;13:2888-2898.

[33] Armen RS, DeMarco ML, Alonso DOV, Daggett V. Pauling and Corey's $\alpha$-pleated sheet structure may define the prefibrillar amyloidogenic intermediate in amyloid disease Proc Natl Acad Sci U S A 2004;101:11622-11627.

[34] Armen RS, Bernard BM, Day R, Alonso DOV, Daggett V. Characterization of a possible amyloidogenic precursor in glutamine-repeat neurodegenerative diseases. Proc Natl Acad Sci USA 2005;102:13433-8.

[35] Armen RS, Alonso DO V, Daggett V. Anatomy of an amyloidogenic intermediate: conversion of beta-sheet to alpha-sheet structure in transthyretin at acidic $\mathrm{pH}$. Structure 2004;12:1847-63.

[36] Daggett V. Alpha-sheet: the toxic conformer in amyloid diseases? Acc Chem Res 2006;39:594-602.

[37] Hopping G et al. Designed alpha-sheet peptides inhibit amyloid formation by targeting toxic oligomers eLife 2014;3:e01681. 
[38] Torii H. Amide i infrared spectral features characteristic of some untypical conformations appearing in the structures suggested for amyloids. J Phys Chem B 2008;112:8737-43.

[39] Cooper G, Willis A. Purification and characterization of a peptide from amyloid-rich pancreases of type 2 diabetic patients Proc Natl Acad Sci U S A 1987;84:8628-8632.

[40] Saraiva MJ. Transthyretin mutations in hyperthyroxinemia and amyloid diseases. Hum Mutat 2001;17:493-503.

[41] LeVine III H. Quantification of $\beta$-sheet amyloid fibril structures with thioflavin T. Methods Enzymol 1999;309:274-284.

[42] Lai Z, Colón W, Kelly J. The acid-mediated denaturation pathway of transthyretin yields a conformational intermediate that can self-assemble into amyloid Biochemistry 1996;35:6470-82.

[43] Beck DAC, Alonso DO V, Inoyama D, Daggett V. The intrinsic conformational propensities of the 20 naturally occurring amino acids and reflection of these propensities in proteins. Proc Natl Acad Sci USA 2008;105:12259-64.

[44] Towse C-L, Hopping G, Vulovic I, Daggett, V. Nature versus design: The conformational propensities of D-amino acids and the importance of side chain chirality. Protein Engineering, Design, and Selection 2014; 27: 447-455.

[45] Ramírez-Alvarado M, Blanco FJ, Serrano L. De novo design and structural analysis of a model beta-hairpin peptide system. Nat Struct Biol 1996;3:604-612.

[46] Sinha S et al. Lysine-specific molecular tweezers are broad-spectrum inhibitors of assembly and toxicity of amyloid proteins. J Am Chem Soc 2011;133:16958-69.

[47] Mishra R, Sjölander D, Hammarström P. Spectroscopic characterization of diverse amyloid fibrils in vitro by the fluorescent dye nile red. Mol Biosyst 2011;7:1232-40.

[48] Gokce I, Woody RW, Anderluh G, Lakey JH. Single peptide bonds exhibit poly(pro)II ("random coil") circular dichroism spectra. J Am Chem Soc 2005;127:9700-1.

[49] Bhaskar $\mathrm{K}$ et al. The pi3k-akt-mtor pathway regulates abeta oligomer induced neuronal cell cycle events. Mol Neurodegener 2009;4:14.

[50] Kusumoto Y, Lomakin A, Teplow DB, Benedek GB. Temperature dependence of amyloid beta-protein fibrillization. Proc Natl Acad Sci USA 1998;95:12277-82.

[51] Pettersen EF, Goddard TD, Huang CC, Couch GS, Greenblatt DM, Meng EC, Ferrin TE. UCSF Chimera--A visualization system for exploratory research and analysis. J Comput Chem. 2004;25:1605-12.

[52] Hopping G, Kellock J, Caughey B, Daggett V. The designed trpzip-3 beta-hairpin inhibits amyloid formation in two different amyloid systems. ACS Med Chem Lett 2013;4:824828. 


\section{Table Legends}

Table 1. Modifications to deconstruct AP90 design features

${ }^{\text {a }}$ Regions of the sequence modified are colored to correspond to the portion of the structure affected, as highlighted in Figure 1. ${ }^{\mathbf{b}}$ Percentage sequence identity relative to AP90 factoring in chirality. ${ }^{\mathrm{c}}$ Percent absolute composition of amino acid side chains (disregarding placement and C $\alpha$ chirality) relative to AP90 (i.e. scrambled sequences produce $100 \%$ sequence composition). ${ }^{\mathrm{d}}$ Measure of the extent (as a percentage) to which $\mathrm{C} \alpha$ chirality matches L/D template (i.e. Damino acids at residues $4,6,8,16,18$, and 20 produce $100 \%$ chirality identity). Note, D-amino acids are distinguished by lower case, underlined letters.

Table 2. Summary of inhibition and binding assays

$\%$ Inhibition values reported as endpoint fluorescence relative to that of the uninhibited control, with the endpoints defined as the endpoint of the lines through the plateau regions, as illustrated in Figure 2. Inhibition and error values are reported over 3 independent aggregation reactions. ${ }^{\mathrm{a}}$ Values apply to co-incubation of $10 \mu \mathrm{M}$ A $\beta 42$ with $40 \mu \mathrm{M}$ inhibitor. ${ }^{\mathbf{b}}$ Values apply to coincubation of $10 \mu \mathrm{M}$ IAPP with $80 \mu \mathrm{m}$ inhibitor. ${ }^{\mathrm{c}}$ Values apply to co-incubation of $40 \mu \mathrm{M}$ TTR monomer with $400 \mu \mathrm{M}$ inhibitor. ${ }^{\mathrm{d}}$ Tally of relative binding of toxic versus nontoxic TTR samples by peptide designs taken from Fig. 3. AP3 does not contain a lysine residue, which is required for coupling to the beads. 
Table 3. Summary of CD spectroscopy results for "templated" peptides

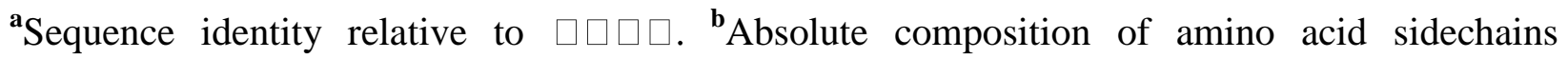
(disregarding placement and C $\alpha$ chirality) relative to AP90 (i.e. scrambled sequences produce $100 \%$ sequence composition). ${ }^{\mathrm{c}}$ Value of the $\mathrm{CD}$ minimum in the $195-200 \mathrm{~nm}\left([\Theta]_{\min }\right)$ region. Negative CD in this region is typically considered a reflection of lack of structure, often referred to as random coil. Sequence identity and composition relative to AP90 are reiterated to compare decreasing $[\Theta]_{\min }$ with increasing randomness-of-design. 


\section{Figure Legends}

Fig. 1. Structural model of AP90. $\alpha$-sheet region is highlighted in yellow. Each of the regions highlighted in either yellow, blue, or red were subject to modification for design of specific peptides. The highlighting on the structure illustrates which sequence segments were modified for each design, and they are color matched with Table 1. Also see Table 1 for specific sequences. The image was generated using UCSF Chimera [51].

Fig. 2. $\alpha$-sheet designs inhibit aggregation in solution. (a) ThT fluorescence time courses obtained from $10 \mu \mathrm{M}$ A $\beta 42$ samples incubated with (red triangles) or without (black squares) a 4-fold excess of inhibitor, respectively. Fluorescence units are normalized to the endpoint of the negative control (black squares), with the endpoint defined as the time at which fluorescence reaches the first local maximum of the curve's plateau region. Samples were incubated at room temperature in PBS (pH 7.4) containing $20 \mu \mathrm{M}$ ThT. (b) ThT fluorescence time courses obtained from $10 \mu \mathrm{M}$ IAPP samples incubated with (blue triangles) or without (black squares) a 8-fold excess of inhibitor. Fluorescence units are normalized to the negative control (black squares) in the same way as for $\mathrm{A} \beta 42$ data. Samples were incubated at $37^{\circ} \mathrm{C}$ in $\mathrm{PBS}(\mathrm{pH} 7.4$ ) containing 20 $\mu \mathrm{M}$ ThT and 4\% DMSO vehicle. (c) CR-binding time courses obtained from $40 \mu \mathrm{M}$ TTR monomer samples incubated with $400 \mu \mathrm{M}$ inhibitor (colored triangles) and without inhibitor (black squares). Additionally, CR-binding time courses for $10 \mu \mathrm{M}$ TTR samples (40 $\mu \mathrm{M}$ monomeric TTR) incubated at neutral $\mathrm{pH}$ (open squares) are shown as a positive inhibition control. Binding units are normalized to the negative control in the same way as for the A $\beta 42$ data. 
Fig. 3. Difference between binding of toxic versus nontoxic solutions of TTR. Peptides were immobilized on agarose beads and either fresh TTR at neutral $\mathrm{pH}$ was applied or TTR incubated at low pH. Toxicity was assayed using SH-SY5Y neuroblastoma cells, as described earlier [37].

Fig. 4. Structural properties of the peptide designs by CD and FTIR. (a) CD spectra of $90 \mu \mathrm{M}$ peptide solutions taken in 50/50 - AcCN/PB (10 mM phosphate, $\mathrm{pH} 7.4)$. Units of molar ellipticity $\left(10^{4} \mathrm{deg} \mathrm{cm}^{2} \mathrm{dmol}^{-1}\right)$ are plotted due to the identical length (23 residues) of all reported peptides. (b) FTIR absorbance spectra (blue). The $1640 \mathrm{~cm}^{-1}$ and $1675 \mathrm{~cm}^{-1}$ absorbance bands associated with $\alpha$-sheet structure are indicated by dashed vertical lines, as is the $1620 \mathrm{~cm}^{-1} \beta$ sheet band.

Fig. 5. Summary of results from solution inhibition assays. The percentage inhibition values are reported as endpoint fluorescence relative to that of the uninhibited control, with the endpoint defined as the time at which fluorescence reaches its first local maximum within the curve's plateau. Sequence identity to AP90 is given beneath the x-axis to correlate changes in the designs with their inhibitory activity; a black to white gradient is included to illustrate decreasing sequence identity (dark to light). Percentage inhibition values are reported as the average of three independent experiments along with reproducibility errors (Table 2). Correlation of CD spectroscopy and inhibition results for "templated" peptide designs. Top curve: Plot of ellipticity minimum at $195-200 \mathrm{~nm}\left([\Theta]_{\min }\right)$ against sequence identity relative to AP90 for all designs. The specific design associated with a sequence identity value is indicated. Bottom curves: Plot of the percentage inhibition against sequence identity relative to AP90. 
Table 1

\begin{tabular}{|c|c|c|c|c|c|}
\hline Design ${ }^{a}$ & Sequence & $\begin{array}{l}\text { Sequence } \\
\text { identity }\end{array}$ & $\begin{array}{l}\text { Sequence } \\
\text { composition. }{ }^{c}\end{array}$ & $\begin{array}{l}\text { Chirality } \\
\text { identity }^{d}\end{array}$ & Description \\
\hline \multicolumn{6}{|c|}{ templated } \\
\hline & Ac-tail-L/D strand-turn-L/D strand-tail-NH & & & & \\
\hline AP90 & 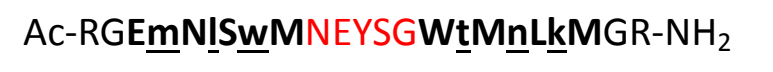 & 100 & 100 & 100 & Parent design \\
\hline AP5 & 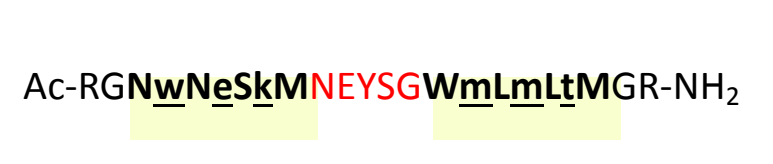 & 65 & 100 & 100 & $\begin{array}{l}\text { Scrambled } \alpha \text {-strand } \\
\text { sequences of AP90 (residues } \\
3-9 \text { and } 15-21 \text { ) }\end{array}$ \\
\hline AP6 & 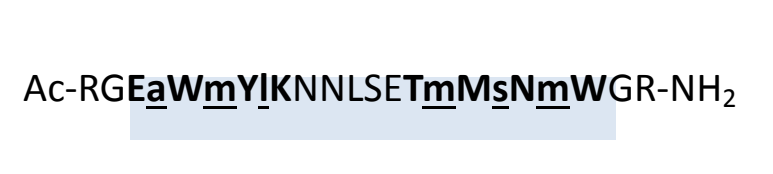 & 25 & 100 & 100 & $\begin{array}{l}\text { Scrambled sequences } \\
\text { through } \alpha \text {-strands and turn of } \\
\text { AP90 (residues 3-21) }\end{array}$ \\
\hline AP3 & 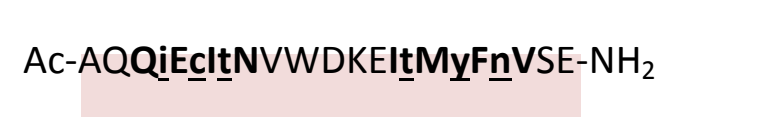 & 16 & 43 & 100 & $\begin{array}{l}\text { Random sequence selection, } \\
\text { maintained L/D template }\end{array}$ \\
\hline AP4 & 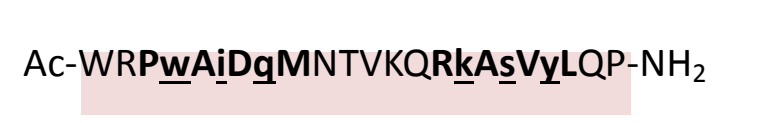 & 9 & 52 & 100 & $\begin{array}{l}\text { Random sequence selection, } \\
\text { maintained L/D template }\end{array}$ \\
\hline \multicolumn{6}{|c|}{ non-templated } \\
\hline P2 & Ac-MNWESkGEE $\underline{w} \mid R M R Y G \underline{t m} L S N G \underline{n} M-N_{2}$ & 24 & 100 & 65 & $\begin{array}{l}\text { Scrambled sequence and } \\
\text { chirality of AP90 }\end{array}$ \\
\hline P90 & Ac-RGEMNLSWMNEYSGWTMNLKMGR-NH ${ }_{2}$ & 100 & 100 & 74 & $\begin{array}{l}\text { All L-amino acid analog of } \\
\text { AP90 }\end{array}$ \\
\hline
\end{tabular}




\begin{tabular}{|c|c|c|c|c|}
\hline Design & $\begin{array}{c}A \beta 42 \\
\% \text { inhibition }^{a}\end{array}$ & $\begin{array}{c}\text { IAPP } \\
\% \text { inhibition }^{b}\end{array}$ & $\begin{array}{c}\text { TTR } \\
\text { \% inhibition }\end{array}$ & $\begin{array}{l}\text { Toxic TTR } \\
\text { Binding }\end{array}$ \\
\hline \multicolumn{5}{|c|}{ templated } \\
\hline AP90 & $95 \pm 3$ & $83 \pm 3$ & $65 \pm 15$ & $\checkmark$ \\
\hline AP5 & $93 \pm 3$ & $92 \pm 3$ & $37 \pm 15$ & $\checkmark$ \\
\hline AP6 & $35 \pm 8$ & $75 \pm 7$ & ND-CR & $V$ \\
\hline AP3 & $11 \pm 4$ & $36 \pm 10$ & ND-CR & ND-No Lys \\
\hline AP4 & $42 \pm 4$ & $11 \pm 13$ & ND-CR & $\checkmark$ \\
\hline
\end{tabular}

non-templated

$\mathrm{P} 2$

P90

$9 \pm 11$
ND-Insoluble

\begin{tabular}{c|}
$13 \pm 20$ \\
ND-Insoluble
\end{tabular}

\begin{tabular}{l|l} 
ND-CR & $\times$ \\
ND-Insoluble & $\times$
\end{tabular}




\section{Table 3}

\begin{tabular}{|c|c|c|c|}
\hline Design & $\begin{array}{l}\text { \%sequence } \\
\text { identity }\end{array}$ & $\begin{array}{l}\text { \%sequence } \\
\text { composition }^{b}\end{array}$ & $\begin{array}{c}{[\Theta]_{\min }\left(10^{4} \mathrm{deg} \mathrm{cm}^{2}\right.} \\
\left.\mathrm{dmol}^{-1}\right)^{\mathrm{c}}\end{array}$ \\
\hline AP90 & 100 & 100 & -7.79 \\
\hline AP5 & 65 & 100 & -10.35 \\
\hline AP6 & 25 & 100 & -13.41 \\
\hline AP3 & 16 & 43 & -16.73 \\
\hline AP4 & 9 & 52 & -14.48 \\
\hline
\end{tabular}




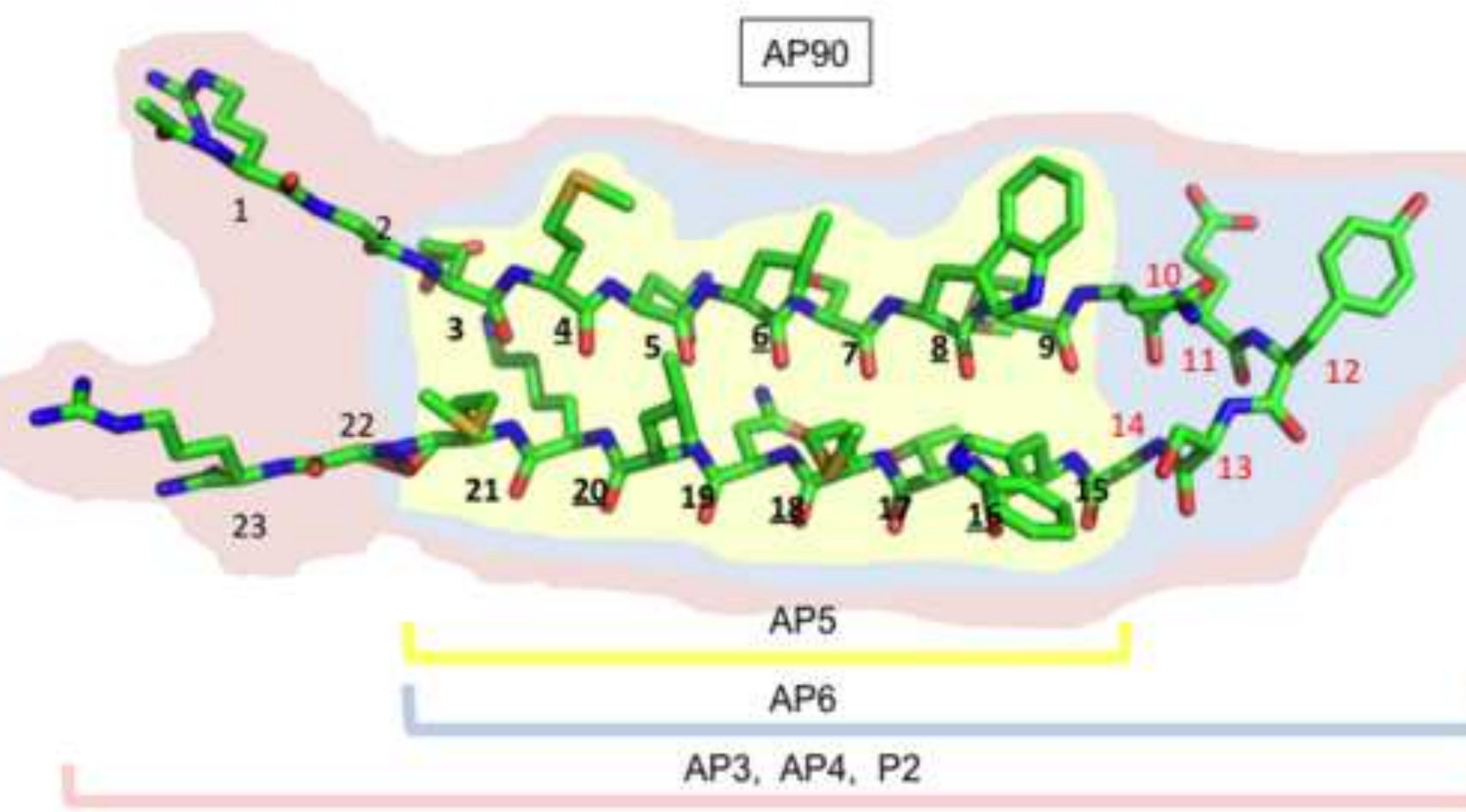

FIGURE 1 
(a)

Design

templated

AP90

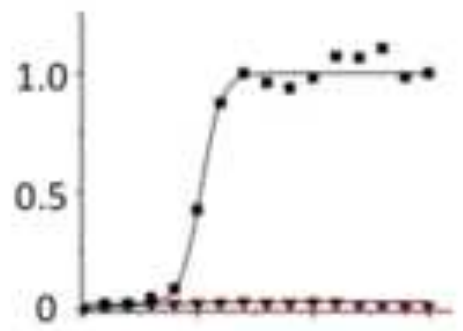

AP5
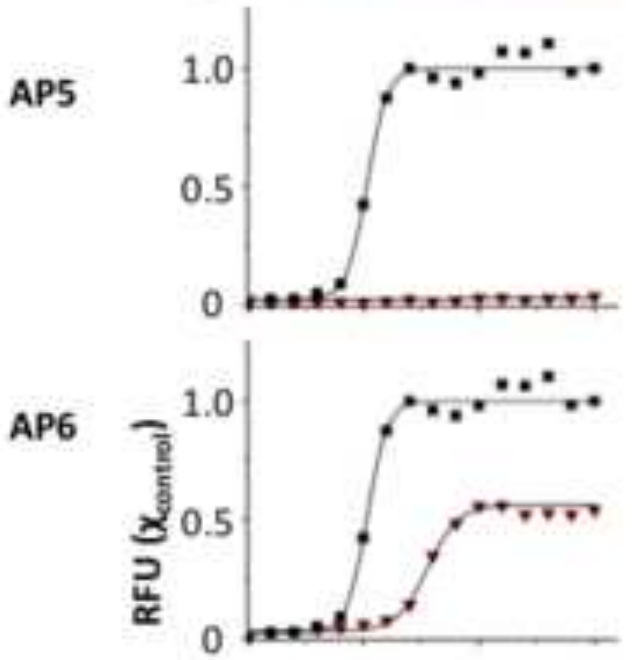

AP3

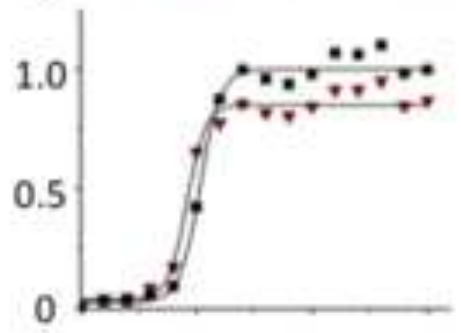

AP4

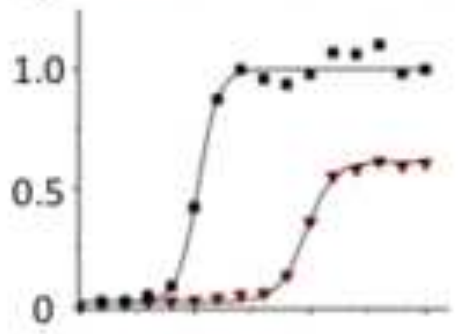

non-temploted

P2

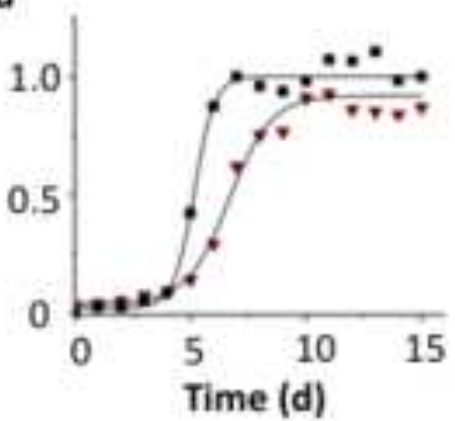

(b)

IAPP

(c)

TIR
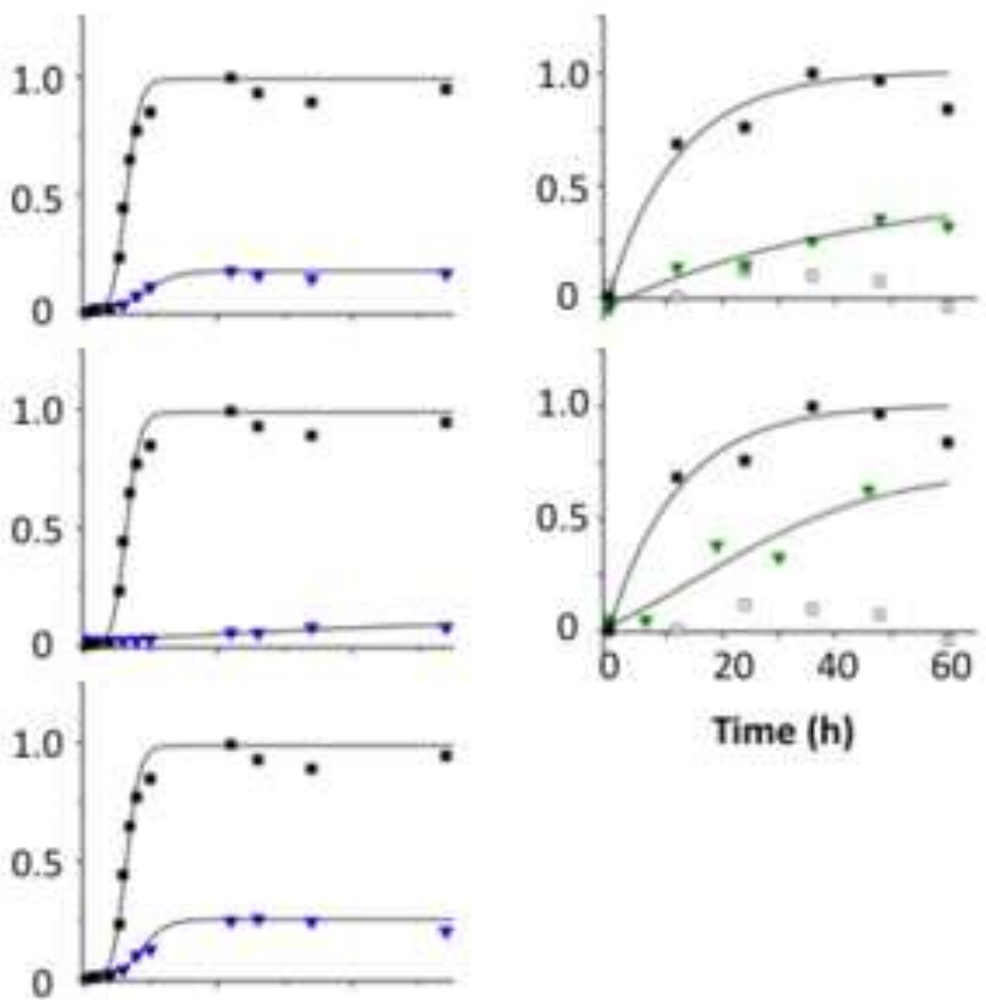

Time (h)
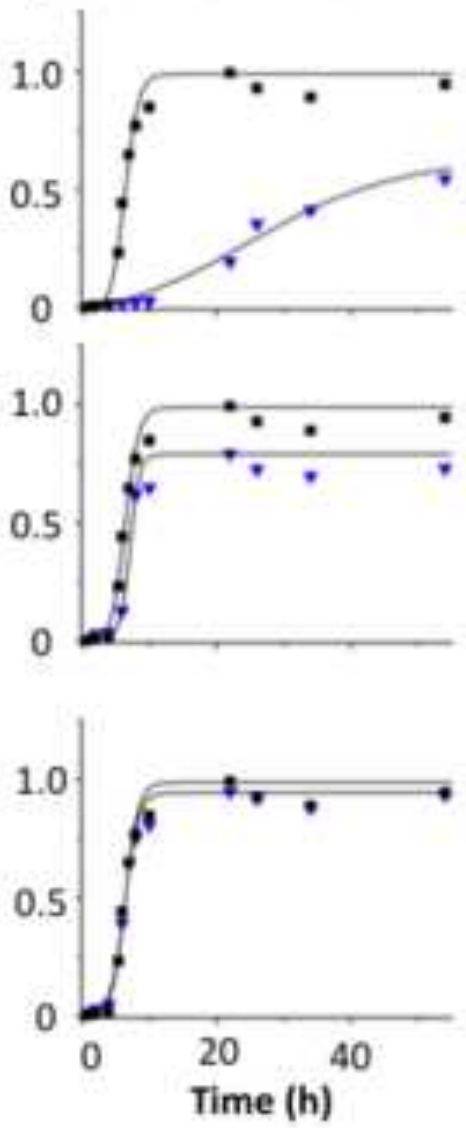

FIGURE 2 


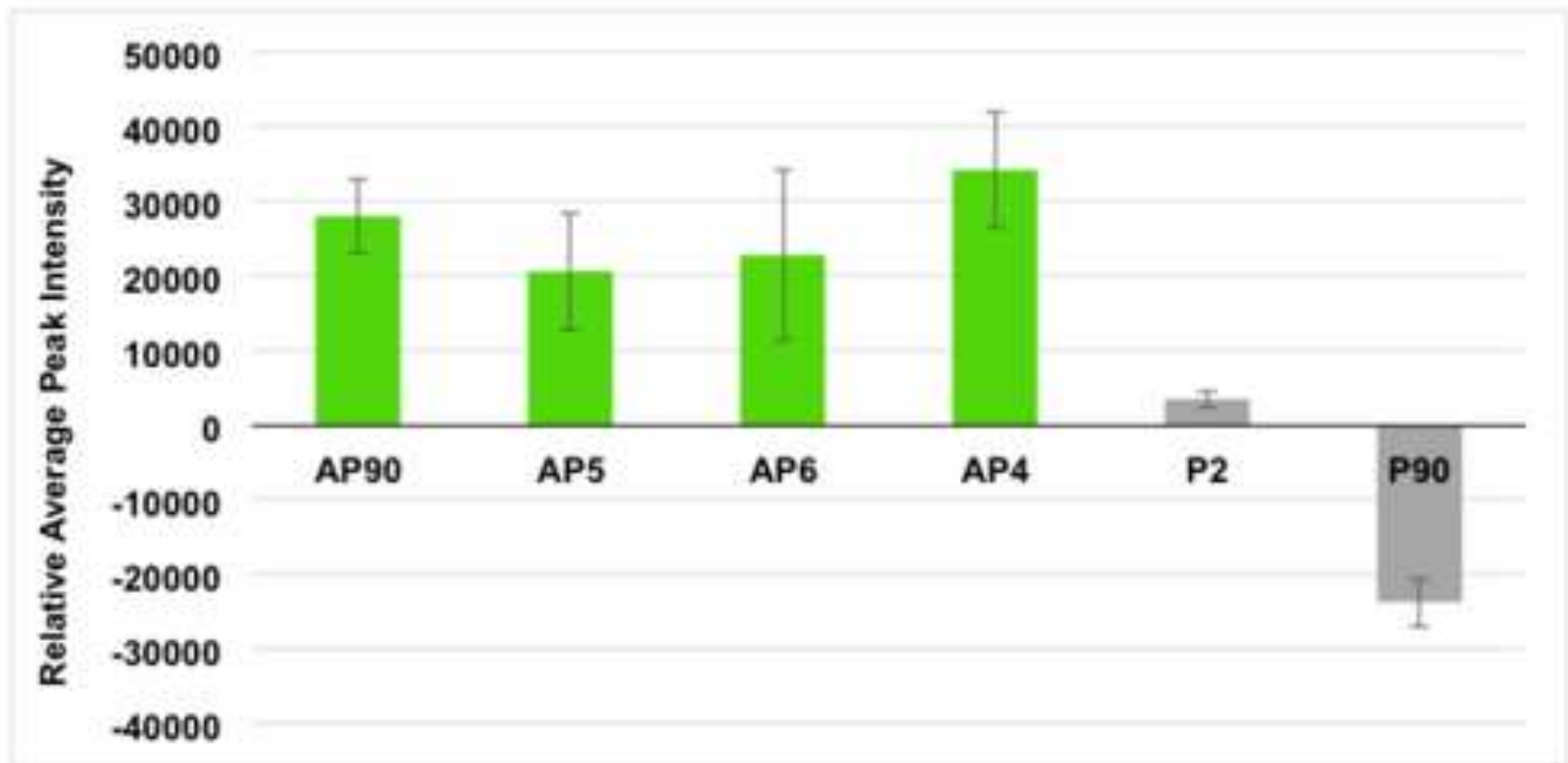

FIGURE 3 


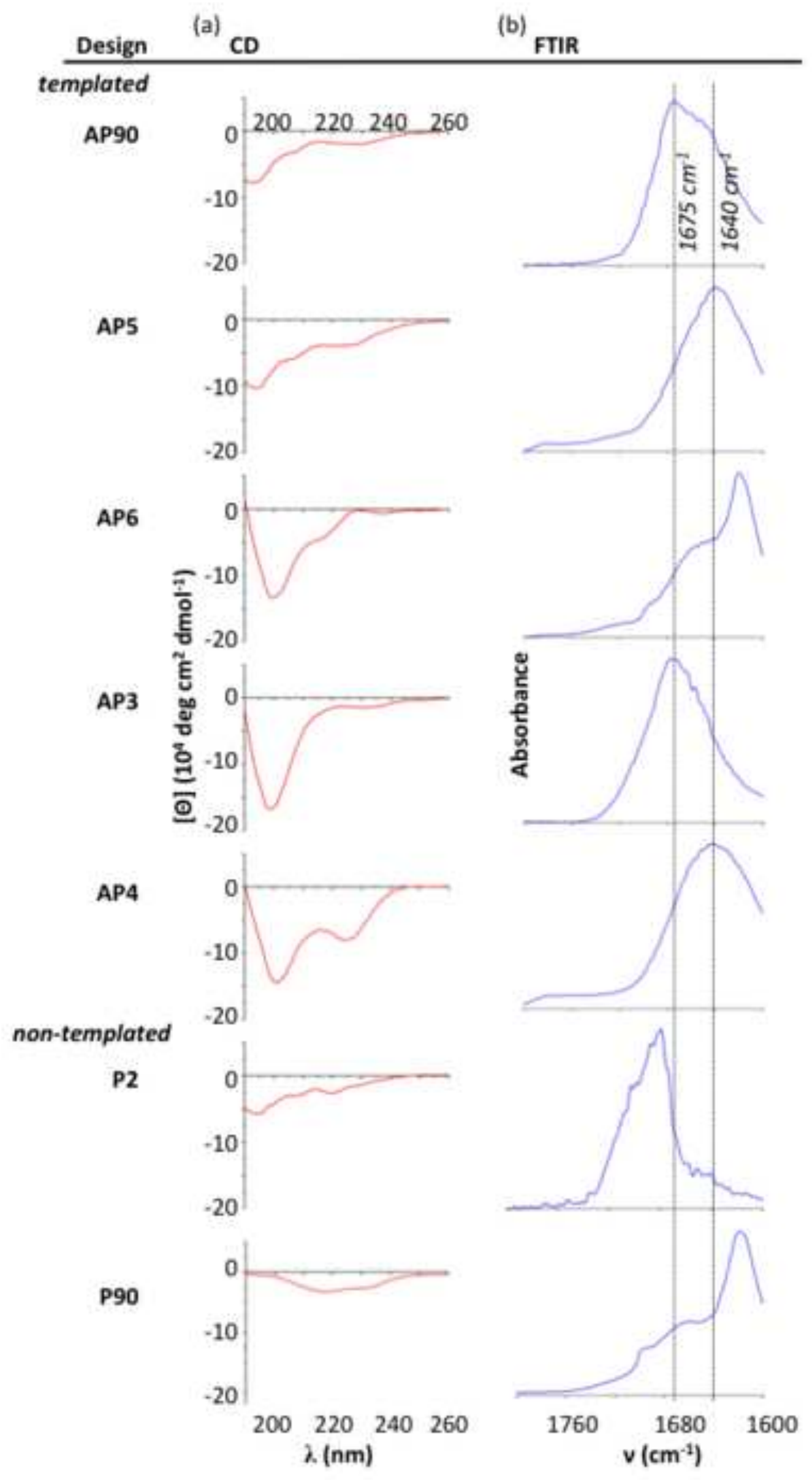

\section{FIGURE 4}



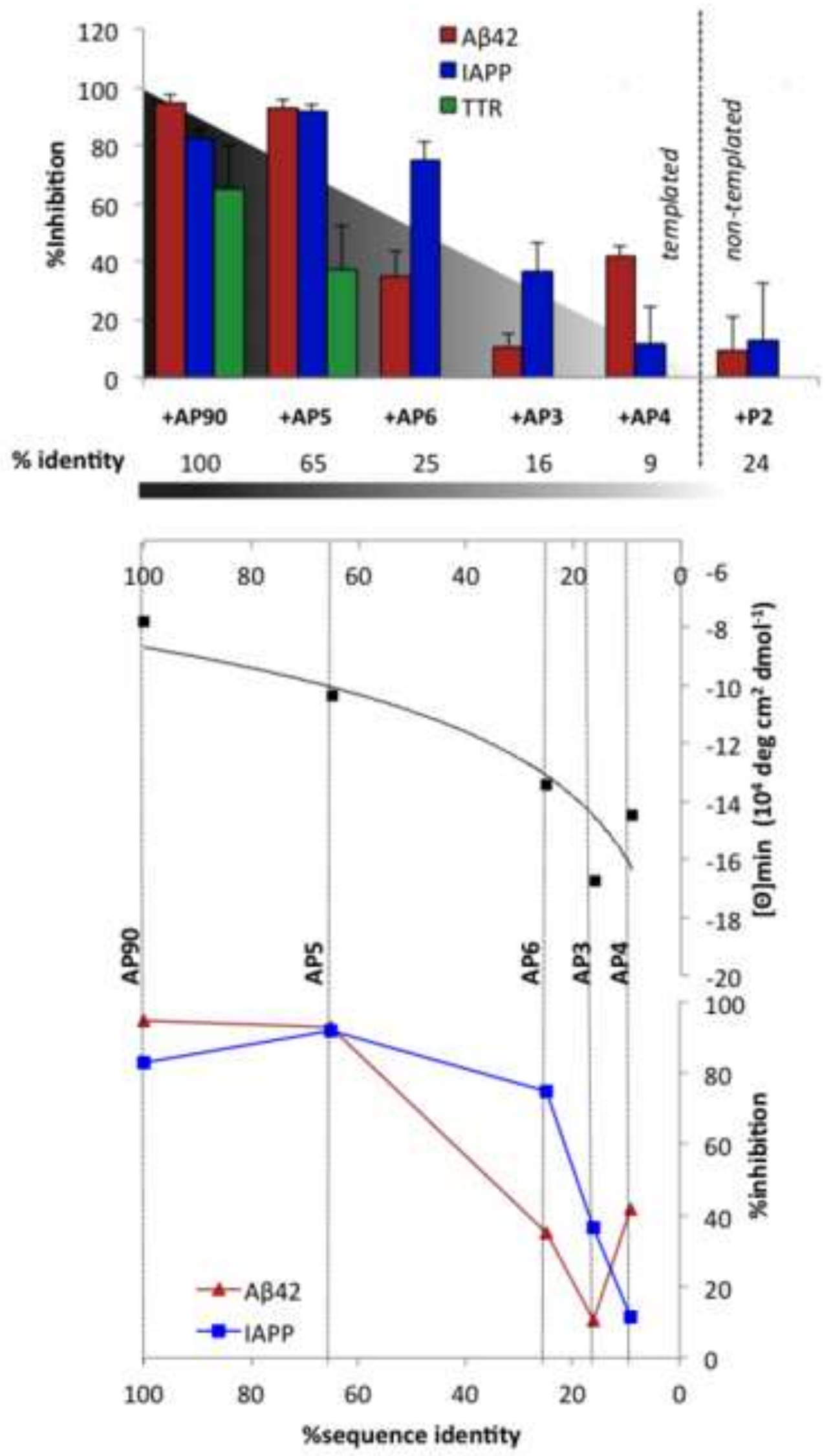

FIGURE 5 